Article

\title{
Microalgae Harvest through Fungal Pelletization-Co-Culture of Chlorella vulgaris and Aspergillus niger
}

\section{Sarman Oktovianus Gultom, Carlos Zamalloa and Bo Hu *}

Department of Bioproducts and Biosystems Engineering, University of Minnesota, 1390 Eckles Ave, MN 55108, USA; E-Mails: gulto002@umn.edu (S.O.G.); czamallo@umn.edu (C.Z.)

* Author to whom correspondence should be addressed; E-Mail: bhu@umn.edu;

Tel.: +1-612-625-4215; Fax: +1-612-624-3005.

Received: 6 June 2014; in revised form: 3 July 2014 / Accepted: 4 July 2014 /

Published: 10 July 2014

\begin{abstract}
Microalgae harvesting is a labor- and energy-intensive process and new approaches to harvesting microalgae need to be developed in order to decrease the costs. In this study; co-cultivatation of filamentous fungus (Aspergillus niger) and microalgae (Chlorella vulgaris) to form cell pellets was evaluated under different conditions, including organic carbon source (glucose; glycerol; and sodium acetate) concentration; initial concentration of fungal spores and microalgal cells and light. Results showed that $2 \mathrm{~g} / \mathrm{L}$ of glucose with a 1:300 ratio of fungi to microalgae provided the best culturing conditions for the process to reach $>90 \%$ of cell harvest efficiency. The results also showed that an organic carbon source was required to sustain the growth of fungi and form the cell pellets. The microalgae/fungi co-cultures at mixotrophic conditions obtained much higher total biomass than pure cultures of each individual strains; indicating the symbiotic relationship between two strains. This can benefit the microbial biofuel production in terms of cell harvest and biomass production.
\end{abstract}

Keywords: co-culture; filamentous fungi; microalgae harvest; pelletization

\section{Introduction}

Microalgae show great potential as a biofuel feedstock due to their capability to utilize $\mathrm{CO}_{2}$, higher biomass yield, and fast growth in open ponds or in bioreactor/fermentation units [1,2]. However, the harvesting process of microalgal cells from cultivation broth is a major problem due to their small size 
$(2-20 \mu \mathrm{m})$ and low density $(0.3-5 \mathrm{~g} / \mathrm{L})$. Various techniques for harvesting microalgae, such as flocculation, flotation, centrifugation, sedimentation, and filtration, as well as combinations of these techniques, have been demonstrated, yet these approaches have limitations for effective and cost-efficient production for biofuel [3].

Microalgal cells are relatively stable and homogeneous when suspended in the cultivation broth. Because of this characteristic, it is difficult to naturally aggregate microalgal cells or settle the cells for harvesting. Co-pelletization of microalgal cells through co-culturing of microalgae with filamentous fungi is a potential technique to harvest microalgae easily and efficiently [4]. Although pelletization of filamentous organisms is more widely used in fungal fermentation, recent studies have revealed that pelletization of filamentous fungi could be applied to harvest microalgal cells. After co-culturing some strains of filamentous fungi with microalgae, it was found that the microalgal cells were either attached or entrapped in the pellets formed by fungi [4]. Of the 12 filamentous fungi cultured together with microalgae, seven had green-colored pellets due to the presence of microalgal cells [4]. Similar work showed that the filamentous fungus Aspergillus oryzae, isolated from municipal wastewater sludge, was able to assist the harvesting process of microalgal cells by forming pellets [5]. The microalgae cells, aggregated with fungal cells, were immobilized in pellets. Results showed that $\mathrm{pH}$ was the key factor affecting the formation of these algae-fungal pellets, which is similar to the previous conclusion that $\mathrm{pH}$ served as the key factor to induce the pelletization of $M$. circinelloides alone [6,7]. Similar results were also obtained with three commercially interesting algal species (C. vulgaris, $C$. sorokiniana, and $S$. vacuolatus) for their compatibility with a previously uncharacterized Sordariomycete to form pellets, which the researchers claim as a symbiotic lichen structure [8].

Although some studies have revealed that certain filamentous fungi had the capability to attract microalgal cells by forming pellets, not much information is available on the culture conditions affecting the cell distribution of the co-pellets. It is very important to measure the harvest efficiency quantitatively under different growth conditions for optimizing the co-culture conditions. In this manuscript, the impact of certain co-culture conditions such as carbon source, medium $\mathrm{pH}$, initial concentration of fungal spores, and initial concentration of microalgal cells on the co-pelletization process are discussed.

\section{Results and Discussion}

\subsection{Description of Pellets Formed during the Co-Culture of C. vulgaris and A. niger}

Filamentous fungus (A. niger) cells were co-cultured with microalgal cells (C. vulgaris) cells together in the shake flasks. Most of cell biomass formed cell pellets. These pellets were sphere-shaped, compact, and relatively homogeneous in size. Compared with the pellets formed only by fungal cells alone, the pellets in the co-culture were green instead of white or grey. The green color of the pellets in the co-culture was due to microalgal cells entrapped in or attached to the pellets during co-cultivation. The microscopic images of the pellets (Figure 1) showed that the microalgal cells were entrapped and attached to the hyphae of the filamentous fungus $A$ niger. The size of the pellets was approximately $2-5 \mathrm{~mm}$; therefore, this technique could potentially provide an easy way to harvest microalgal cells through a simple filtration with sieves. 
Figure 1. Light microscopy images of fungus-microalgae pellets. (a) Overview of the surface of filamentous hyphae of Aspergillus niger and Chlorella vulgaris. (b) Magnification of image (a). Arrows indicate C. vulgaris cells.


\subsection{Effects of Different Carbon Sources on the Co-Culture Process}

\subsubsection{Glucose}

Experiments with different concentrations of glucose as the only carbon source showed that the harvest efficiency of microalgae was more than $>80 \%$ for all cultures with glucose concentration higher than $1 \mathrm{~g} / \mathrm{L}$; while for the cultures with $1 \mathrm{~g} / \mathrm{L}$ of glucose, the harvest efficiency was approximately $35 \%$ (Figure 2). With a higher concentration of glucose, the size of the pellets formed in the co-culture is larger, and the total number of the pellets increases as well (Table 1). The increased concentration of glucose provided a sufficient carbon source to sustain the cell growth, especially the fungal cells, which therefore resulted in better pelletization and harvest efficiency.

Figure 2. Fungi and microalgae in the co-culture and the pure culture at different glucose concentrations under heterotrophic conditions.

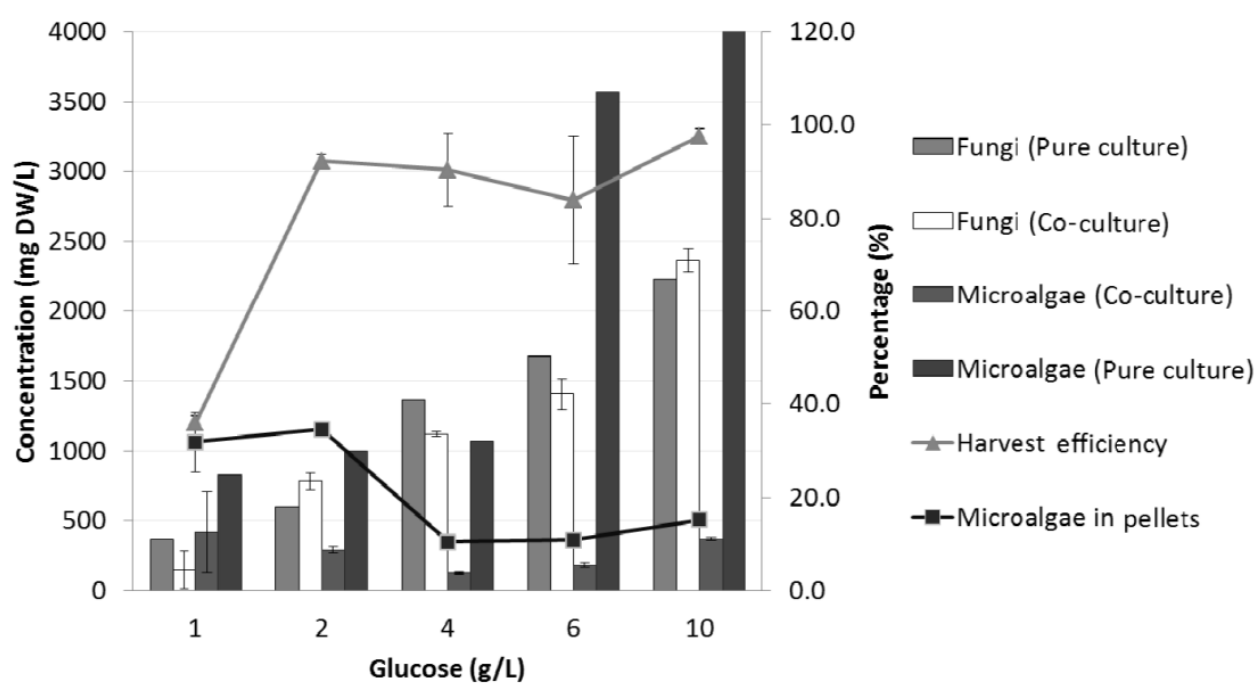


Table 1. Pellets and $\mathrm{pH}$ in the co-culture at different glucose concentrations under heterotrophic conditions.

\begin{tabular}{cccccc}
\hline \multirow{2}{*}{ Co-culture } & \multicolumn{5}{c}{ Glucose concentration (g/L) } \\
\cline { 2 - 6 } & 1 & 2 & 4 & 6 & 10 \\
\hline \# of pellets/mL & $2 \pm 0.2$ & $5 \pm 1.5$ & $6 \pm 0.7$ & $7 \pm 0.7$ & $7 \pm 0.8$ \\
Average diameter $(\mathrm{mm})$ & $3 \pm 0.1$ & $3.3 \pm 0.3$ & $3.4 \pm 0.2$ & $3.6 \pm 0.8$ & $3.8 \pm 0.4$ \\
Average final pH & $7.1 \pm 0.0$ & $7.1 \pm 0.2$ & $5.6 \pm 0.9$ & $4.1 \pm 0.1$ & $4.0 \pm 0.2$ \\
\hline
\end{tabular}

The percentage of microalgal cells out of pellets was very low, and it is even significantly lower if the glucose concentrations were higher, as in the cases of 4-, 6-, and 10-g/L concentrations (Figure 2). Table 1 showed that the pure fungal cultures resulted in a much lower final $\mathrm{pH}$ with a higher dose of glucose, similar to the co-culture, while the pure culture of microalgae cells did not cause the significant decrease of final $\mathrm{pH}$ even with an elevated glucose input. The filamentous fungus $A$. niger was reported to be able to oxidize glucose to gluconic acid and 2-ketogluconic acid, which may be a reason for the acidic condition in the culture [9]. The lower microalgae cell content in the co-pellets at higher glucose concentration could be caused by the strong inhibition of microalgae growth at the acidic condition (around a pH of 4) (Table 1).

The glucose consumption profiles in the co-culture and in the pure culture of individual fungus and microalgae are very similar (Figure 3), indicating a competition for glucose between fungal and microalgae cells. Under heterotrophic conditions, both cells need an organic carbon source to sustain their growth, thus the competition between A. niger and C. vulgaris for the glucose in the co-culture cannot be avoided. It also appeared that the concentration of fungal biomass in the co-culture was relatively higher at higher glucose concentrations (Figure 2). This high concentration can be confirmed by the much faster glucose consumption rate by the fungus than that by the microalgae when the amount of glucose was abundant (Figure 3), possibly because of the metabolic capacity of fungi that allows them to utilize the glucose more effectively [10]. When the concentration of glucose increased up to $10 \mathrm{~g} / \mathrm{L}$, the productivity of the fungus $\left(790 \mathrm{mg} \cdot \mathrm{L}^{-1} \cdot\right.$ day $\left.^{-1}\right)$ was approximately seven times higher than the productivity of the microalgae $\left(115 \mathrm{mg} \cdot \mathrm{L}^{-1} \cdot\right.$ day $\left.^{-1}\right)$. With higher concentrations of glucose, the fungal biomass concentration in the co-culture was still the same as that in the pure culture of only fungi, whereas the microalgal biomass in the co-culture was much lower compared with the biomass produced in the pure culture of only microalgae (Figure 2). This finding further confirmed that fungal cells gained significant overgrowth when the glucose concentration was higher.

Based on these results, a glucose concentration of $2 \mathrm{~g} / \mathrm{L}$ was identified as the optimum concentration for co-pelletization. With $2 \mathrm{~g} / \mathrm{L}$ of glucose, the harvest efficiency of microalgae can reach up to more than $90 \%$ without decreasing the $\mathrm{pH}$ to acidic conditions. The number of pellets in the co-culture was $5 \pm 1.5$ pellets $/ \mathrm{mL}$ with an average diameter of $3.3 \pm 0.3 \mathrm{~mm}$. When comparing the final concentration of microalgae at $2 \mathrm{~g}$ glucose/L with the initial concentration in the co-culture, it was observed that the final concentration of microalgae was approximately 300 times higher than the initial concentration with a biomass productivity near $90 \mathrm{mg} \cdot \mathrm{L}^{-1} \cdot \mathrm{day}^{-1}$. In the pure culture, however, the final concentration of microalgae was approximately 1,000 times higher than the initial concentration, with a biomass productivity around $320 \mathrm{mg} \cdot \mathrm{L}^{-1} \cdot \mathrm{day}^{-1}$. Results from other studies 
showed that the maximum biomass productivity of C. vulgaris under heterotropic conditions with $1 \%$ of glucose was $151 \mathrm{mg} \cdot \mathrm{L}^{-1} \cdot$ day $^{-1}[11]$.

Figure 3. Glucose concentration profile versus cultivation time. (a) Pure fungus. (b) Pure microalgae. (c) Co-culture (fungus and microalgae).
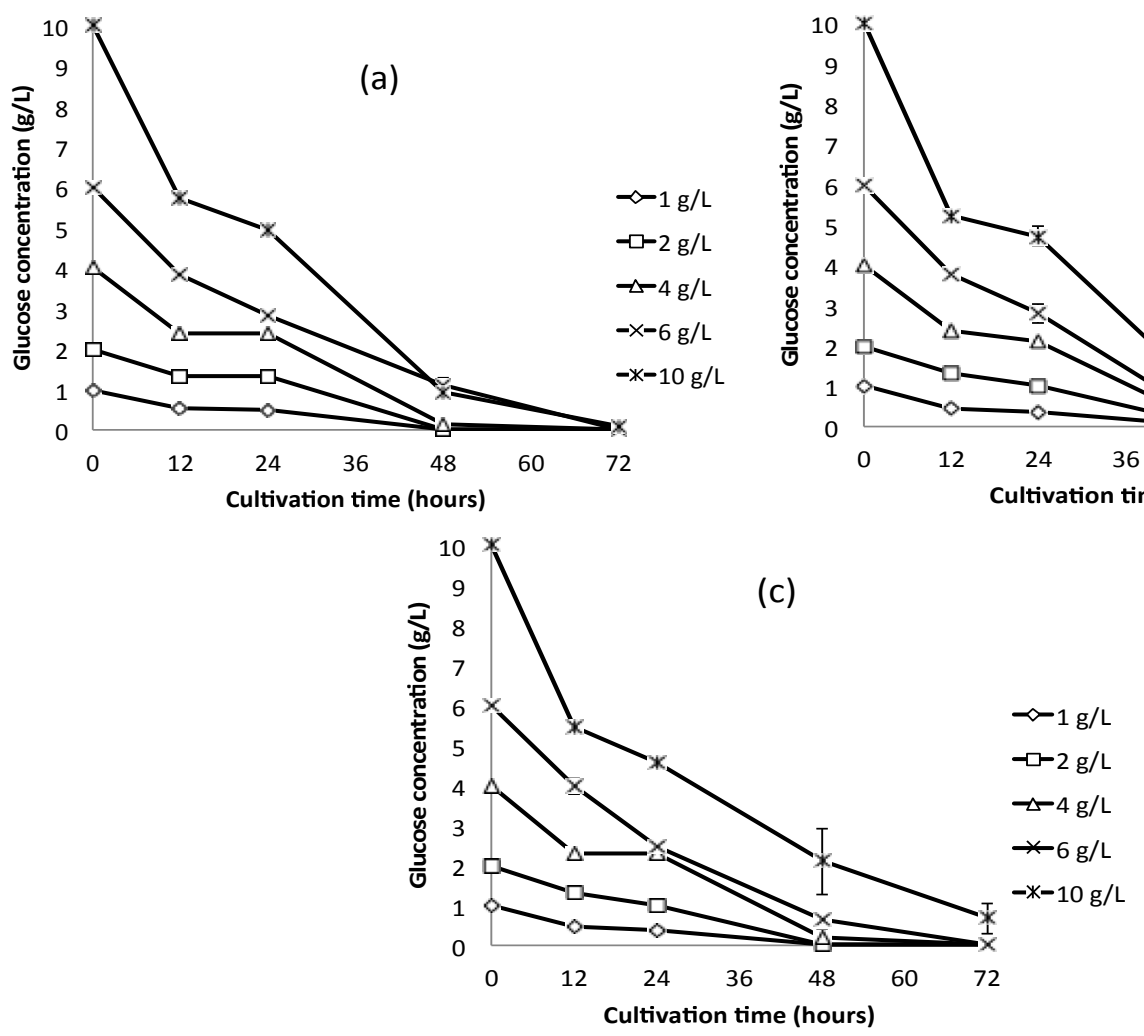

(c)

(b)

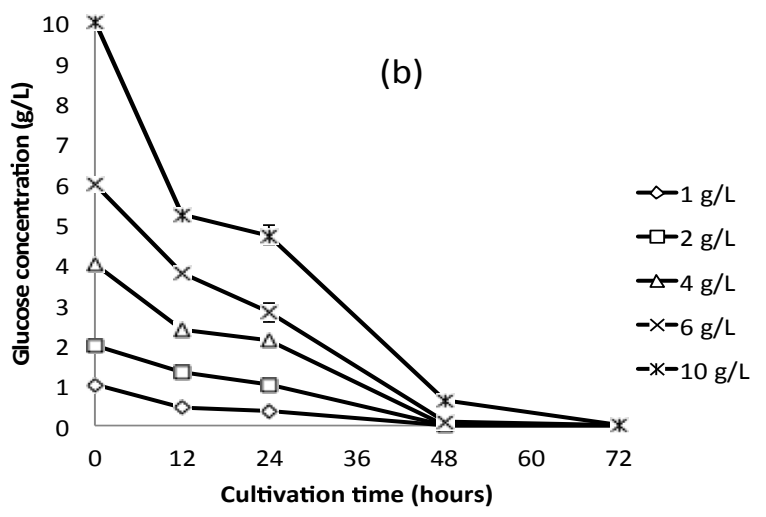

$$
\begin{aligned}
& \curvearrowright-1 \mathrm{~g} / \mathrm{L} \\
& -\square-2 \mathrm{~g} / \mathrm{L} \\
& -\triangle-4 \mathrm{~g} / \mathrm{L} \\
& -\times-6 \mathrm{~g} / \mathrm{L} \\
& -*-10 \mathrm{~g} / \mathrm{L} \\
&
\end{aligned}
$$


Figure 4. Harvest efficiency and microalgae/fungi cell distribution in the pellets from the co-culture with glycerol and sodium acetate as carbon sources under heterotrophic conditions.

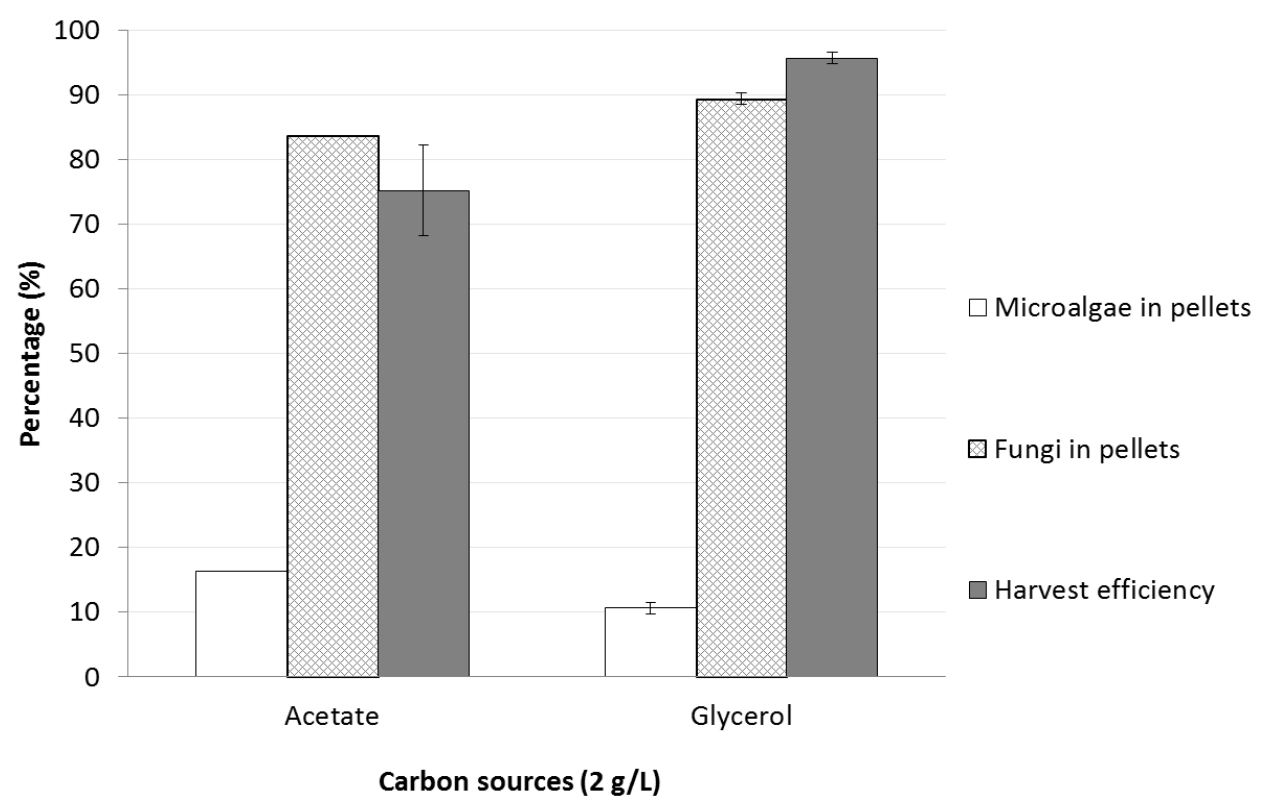

\subsection{Effects of Initial Fungal Spore Concentration on the Co-Culture}

Pellets were formed at all cultures with different tested concentrations of fungal spore inoculum. The harvest efficiency was almost $100 \%$ for all the tests, except for those at $2.50 \times 10^{6}$ fungal spores/L, which corresponds to the fungus to microalgae ratio of 1:1,000 (Figure 5). The co-culture broth was clearly green at this specific condition, which indicated that most of the microalgal cells were still suspended in the medium. Moreover, the number of pellets formed at this condition was relatively small (approximately four pellets/mL) (Table 2), and the percentage of fungal biomass from pellets was also less (Figure 5). These findings indicate that the concentration of fungal spores has to reach a certain level, for higher harvest efficiency. The inoculum concentration of fungal spores was reported to affect the formation of pellets [12]. This experimental result also shows that co-pelletization is similar to fungal pelletization, where the inoculum concentration of fungal spores affects the size and number of pellets [13].

Table 2. Number and diameter of pellets in the co-culture at different fungus-to-microalgae ratios under heterotrophic conditions.

\begin{tabular}{cccccc}
\hline \multirow{2}{*}{ Co-culture } & \multicolumn{5}{c}{ Fungi:microalgae ratio } \\
\cline { 2 - 6 } & $1: 50$ & $1: 100$ & $1: 300$ & $1: 600$ & $1: 1,000$ \\
\hline \# of pellets $/ \mathrm{mL}$ & $6 \pm 0.6$ & $5 \pm 2.8$ & $5 \pm 0.2$ & $4 \pm 0.4$ & $4 \pm 0.8$ \\
Average diameter $(\mathrm{mm})$ & $2.6 \pm 0.4$ & $2.9 \pm 0.4$ & $3.4 \pm 0.2$ & $3.6 \pm 0.9$ & $3.6 \pm 0.6$ \\
\hline
\end{tabular}

It was observed that the decrease of the initial concentration of fungal spores from $4.25 \times 10^{6}$ spores/L (ratio of $1: 600$ ) to $2.50 \times 10^{6}$ spores/L (ratio of 1:1,000), clearly decreases the concentration of total fungal biomass (Figure 5). However, a lower inoculum concentration of fungal 
spores increased the concentration of total microalgal biomass. A lower concentration of fungal spores clearly favored microalgal cells in the competition for carbon source (i.e., glucose) (Figure 5). The initial spore concentration of $8.50 \times 10^{6}$ spores/L was found to be suitable for co-pelletization in terms of harvest efficiency ( $>95 \%)$ and for the total concentration of both fungal and microalgal biomass.

Figure 5. Fungal and microalgae in the co-culture and the pure culture at different fungus:microalgae ratio under heterotrophic conditions.



\subsection{Effects of Initial Microalgal Cell Concentration on the Co-Culture Process}

For the co-culture with a higher inoculum concentration of microalgal cells $\left(3.83 \times 10^{9}, 4.46 \times 10^{9}\right.$ and $8.50 \times 10^{9}$ cells/L), the harvest efficiency significantly dropped to $62 \%, 27 \%$ and $0.7 \%$, respectively (Figure 6). As shown in Figure 9a, the percentage of microalgae entrapped in the pellets was lower when the initial concentration of microalgal cells in this experiment was either very low $\left(4.25 \times 10^{8}\right.$ cells/L) or very high $\left(8.50 \times 10^{9}\right.$ cells $\left./ \mathrm{L}\right)$. Due to the low initial concentration of microalgal cells, the latter might be easily entrapped in the fungal hyphae. However, a high initial concentration of microalgal cells $\left(8.50 \times 10^{9}\right.$ cells/L) could affect the concentration of total fungal biomass as well as the total microalgal biomass (Figure 6). It was found that the concentration of total fungal biomass is clearly decreased when the initial microalgal concentration of $8.50 \times 10^{9}$ cells/ $\mathrm{L}$ was used. The number and the size of pellets as shown in Table 3 also confirmed this result, with a drastic decrease in the number and size of pellets when a high initial concentration of $8.50 \times 10^{9}$ cells/ $\mathrm{L}$ of microalgal cells was used.

Table 3. Number and diameter of pellets in the co-culture at different initial microalgal cell concentrations under heterotrophic conditions.

\begin{tabular}{ccccccc}
\hline \multirow{2}{*}{ Co-culture } & \multicolumn{5}{c}{ Initial concentration of microalgal cells (cells/L) } \\
\cline { 2 - 6 } & 0 & $4.25 \times 10^{8}$ & $2.55 \times 10^{9}$ & $3.83 \times 10^{9}$ & $4.46 \times 10^{9}$ & $8.50 \times 10^{9}$ \\
\hline \# of pellets $/ \mathrm{mL}$ & $5 \pm 1.2$ & $5 \pm 1.1$ & $4 \pm 0.5$ & $4 \pm 0.4$ & $3 \pm 0.4$ & $1 \pm 0.4$ \\
Average diameter $(\mathrm{mm})$ & $3.5 \pm 2.1$ & $3.4 \pm 0.1$ & $3.3 \pm 0.1$ & $3.3 \pm 0.3$ & $3.0 \pm 0.8$ & $2.5 \pm 0.1$ \\
\hline
\end{tabular}


Although the initial concentration of fungus as well as of microalgae was applied based on the same ratio of fungus to microalgae (ratio of 1:1,000), the number and diameter of pellets formed were different. For lower initial concentrations of fungus with a constant initial concentration of microalgae (fungus to microalgae ratio of 1:1,000), the number and the diameter of pellets were larger ( $4 \pm 0.8$ pellets $/ \mathrm{mL}$ and $3.6 \pm 06 \mathrm{~mm}$, respectively) than the number and the diameter of pellets for higher initial concentrations of microalgae with a constant initial concentration of fungus (fungus to microalgae ratio of 1:1,000), $1 \pm 0.4$ pellets $/ \mathrm{mL}$ and $2.5 \pm 0.1 \mathrm{~mm}$, respectively. This finding suggested that the concentration of microalgae applied to the co-culture affects the number and the diameter of pellets.

Figure 6. Fungal and microalgae in the co-culture and pure culture at different initial microalgal cell concentrations under heterotrophic conditions.

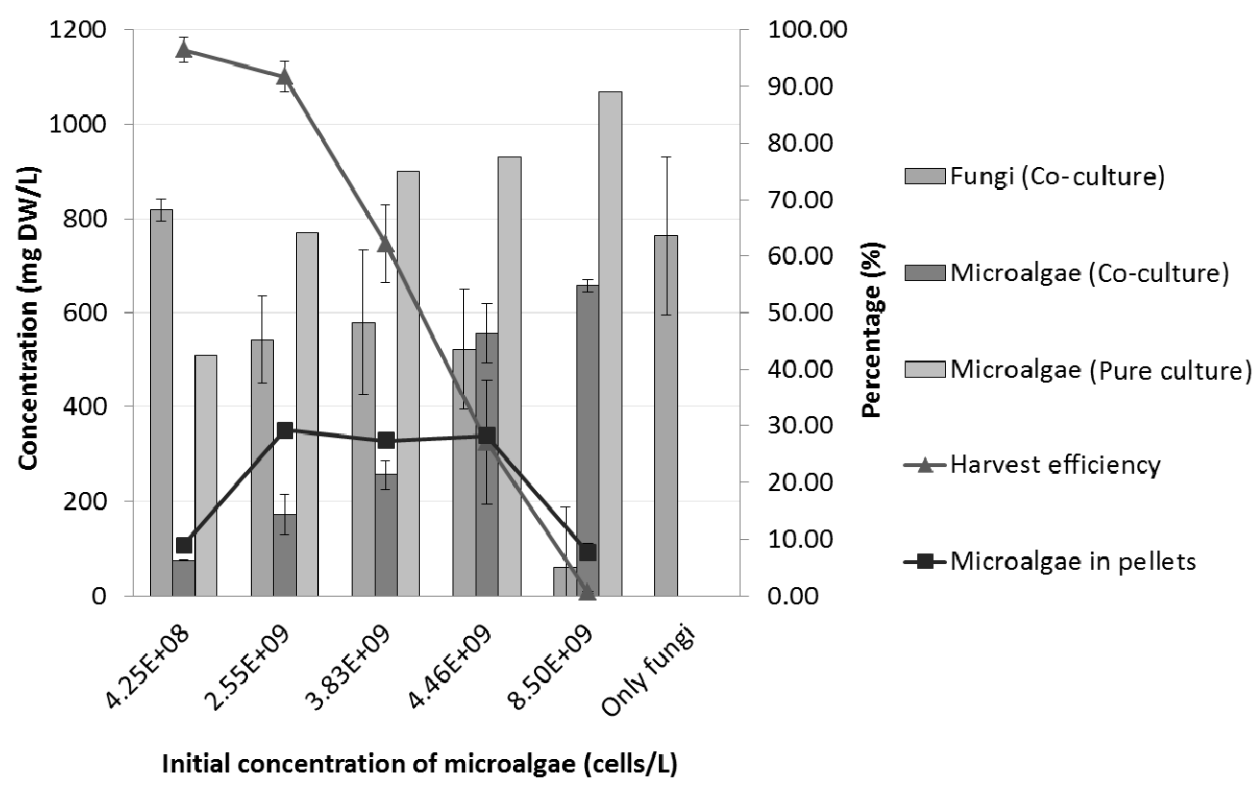

From this study, the initial microalgal cell concentration of $2.55 \times 10^{9}$ cells $/ \mathrm{L}$ was found to be the best concentration for co-pelletization. A previous co-pelletization study carried out by the research group did not quantify the inoculum concentration of microalgae cells used in the co-culture, but instead used $20 \mathrm{~mL}$ of microalgae broth for all experiments [4]. Another study on fungus-microalgae pelletization also did not mention the initial concentration of microalgae used in the co-culture [7]. It is important to note that the initial concentration of microalgae could affect the efficiency of microalgae harvesting as well as the morphology of the pellets. By applying this concentration, a harvest efficiency of $>90 \%$ was obtained without decreasing the total concentration of both fungal and microalgal biomass. Hence, this initial microalgal cell concentration will be used in the subsequent future experiments.

\subsection{Effects of Light on the Co-Culture Process}

After 3 days of phototrophic cultivations, no pellets were formed in the co-culture with either yeast extract or glucose, whereas pelletization did occur in the co-culture medium containing yeast extract with or without glucose. In the absence of yeast extract and glucose, the growth of microalgae was 
very slow and the fungal spores were not germinated. It was obvious that co-pelletization fully depended on the presence of an organic carbon and nitrogen source. An addition of $0.5 \mathrm{~g} / \mathrm{L}$ of yeast extract could induce the growth of fungal spores. This finding signifies that the fungus could use yeast extract as both energy and nitrogen source in order to germinate the spores to form pellets. In the same way, during the co-culture experiments, the concentration of microalgal biomass with glucose was 3 times and 10 times higher with glucose than without glucose and without both yeast extract and glucose, respectively (Figure 7). These results suggest that co-pelletization would not occur in phototrophic cultivation without the addition of a carbon source.

Figure 7. Phototrophic co-cultivation of fungal and microalgae under different conditions.

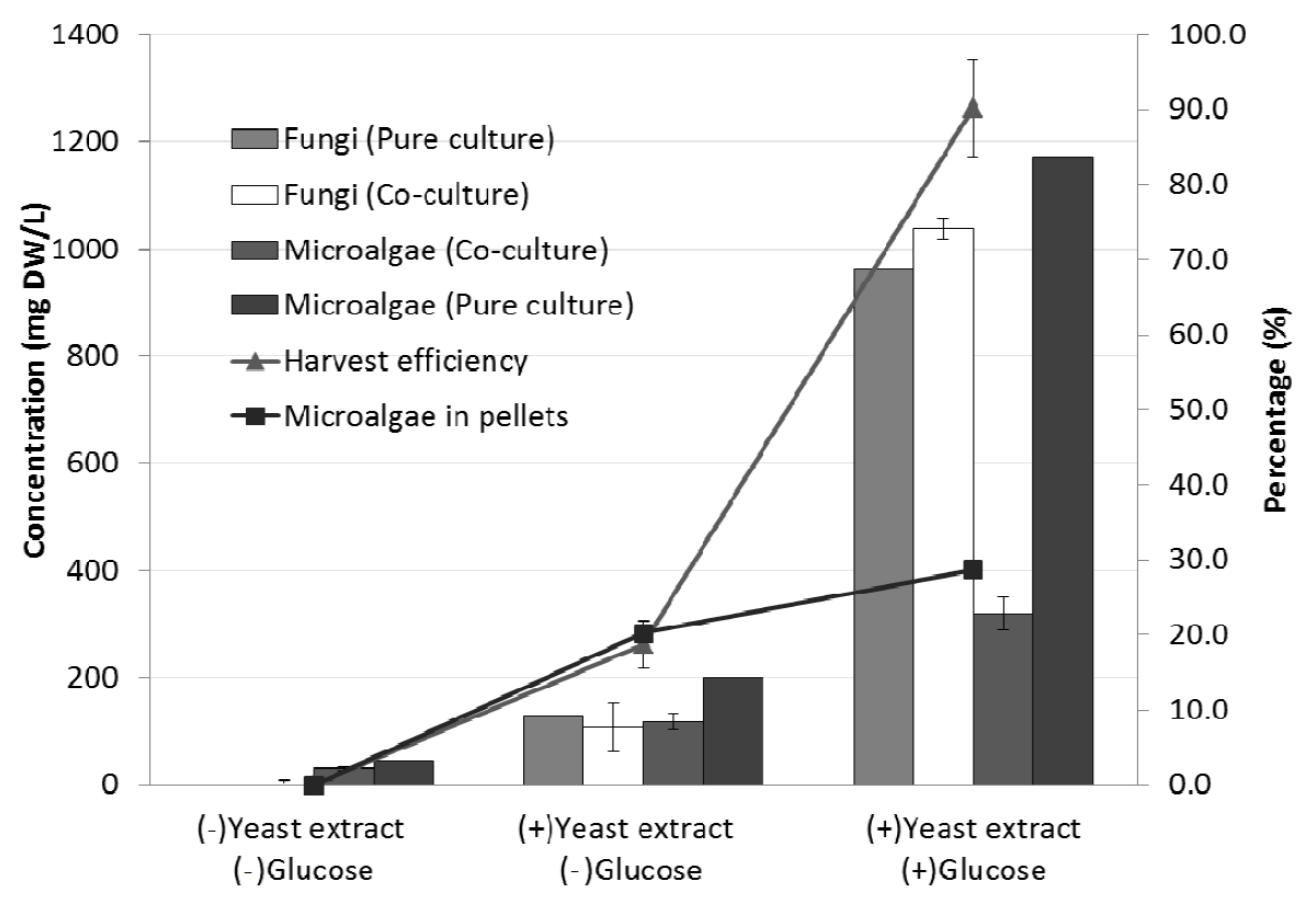

Phototrophic conditions

Even so, in terms of harvest efficiency, pellets formed in the yeast extract medium could not harvest the microalgal cells as efficient as pellets formed in the co-culture medium with both yeast extract and glucose (Figure 7). The concentration of total fungal biomass during the co-culture with $2 \mathrm{~g} / \mathrm{L}$ of glucose was almost 10 times higher than the co-culture without glucose (Figure 7), and the harvest efficiency increased 50\% from the co-culture without glucose and 90\% from the co-culture without both yeast extract and glucose. The composition of the pellets also significantly shifted from equal share of microalgae/fungi cells to fungi dominance, with addition of glucose. Therefore, carbon addition specifically gives growth preference on fungal cells, which caused much higher harvesting efficiency, but lower share of the microalgae biomass in the cell pellets.

Mixotrophic cultures combine features from both autotrophic cultures where microalgae rely on light to grow and the heterotrophic cultures where microalgae and fungi rely on organic carbon for their energy need. The co-culture at the mixotrophic conditions where microalgae cells can access both light and organic carbon to support their growth can be very complicated. Unlike some microalgae species, such as Chlorella protothecoides, which can only grow with heterotrophic if sugar is provided [14], C. vulguris can grow both on light and organic carbon [15]. At mixotrophic conditions, fungi will 
form a symbiotic relationship with autotrophic microalgae cells while competing for nutrients with heterotrophic algae cells. The fungal biomass in these co-cultures was about similar to that of pure culture of fungi, which indicates that the final fungal biomass concentration was determined by the carbon source in this cultural medium (Figure 7). The algae biomass in the co-cultures was lower than that of the pure cultures, due to the nutrient competition between microalgae and fungi cells (Figure 7). In context of competition of nutrients, neither fungi nor microalgae cells will reach to their maximized growth compared with their growth in the pure culture of these strains individually. The total biomass (both microalgae and fungi) was significantly higher in the co-cultures than pure cultures of either fungi or microalgae. The mixotrophic co-cultures obtained several times higher microalgae biomass than the pure culture of microalgae (Figure 7) even though the amount of the fungal biomass obtained from the co-cultures was similar as the ones with the pure fungal culture. This can primarily be attributed to the symbiosis between microalgae and fungal cells, which occur mostly in the autotrophic growth of microalgae via photosynthesis. The co-cultivation of fungal cells stimulated the overall microalgae cultivation and dramatically increased the final algae cell concentration. A $2 \mathrm{~g} / \mathrm{L}$ of glucose input into the culture medium was a cost compared to the significant gain of the final microalgae biomass concentration. Large scale microalgae cultures for biofuel production are mainly proposed to be based on phototrophic conditions, even though some mixotrophic/heterotrophic approaches are also studied to target on the utilization of nutrients in the wastewater. Adding large amount of organic carbons will not be economically feasible and keeping the glucose input at lower levels should be recommended. In terms of nutrient competition, to identify the optimal glucose concentration under mixotrophic conditions as an approach for population control of an individual strain needs to be further studied. The microalgae/fungi co-pelletization process is innovative, but limited. It enables microalgae to aggregate with assistance of filamentous fungi and form self-immobilized cell pellets. Current studies are still primarily in the laboratory and the culture conditions are limited to shaking environments. Knowledge of how to scale up the co-pelletization process using the optimum conditions found in the laboratory study will also be needed in order to make this method more economically attractive and viable to the industry.

\section{Experimental Section}

\subsection{Cell Cultivation of Microalgae and Fungal Strains}

The microalgae strain Chlorella vulgaris (UTEX 2714) and the fungal strain Aspergillus niger (Ted S-OSU) were used in this study. A. niger spores were cultivated at $27 \pm 2{ }^{\circ} \mathrm{C}$ in potato dextrose medium based on previous work by Zhang and $\mathrm{Hu}$ [4]. The effect of different carbon sources, glucose concentration, initial fungi inoculum concentration, and initial microalgae inoculum concentration under heterotrophic co-culture conditions was studied. Experiments in triplicates were conducted in a 250-mL Erlenmeyer flask with $100-\mathrm{mL}$ working volume in an incubator shaker at $27 \pm 2{ }^{\circ} \mathrm{C}$. Erlenmeyer flasks were shaken for a process period of 3 days at $150 \mathrm{rpm}$. Control experiments consisting of pure microalgae and fungi were included in each set of experiments in duplicates. Unless indicated, the composition of the culture medium used was (1 L distilled water): $2 \mathrm{~g}$ glucose, $1 \mathrm{~g} \mathrm{KNO}_{3}, 0.075 \mathrm{~g} \mathrm{KH}_{2} \mathrm{PO}_{4}, 0.1 \mathrm{~g} \mathrm{~K}_{2} \mathrm{HPO}_{4}, 0.5 \mathrm{~g} \mathrm{MgSO}_{4} \cdot 2 \mathrm{H}_{2} \mathrm{O}, 0.0625 \mathrm{~g} \mathrm{Ca}\left(\mathrm{NO}_{3}\right)_{2} \cdot 4 \mathrm{H}_{2} \mathrm{O}, 0.01 \mathrm{~g}$ 
$\mathrm{FeSO}_{4} \cdot 7 \mathrm{H}_{2} \mathrm{O}, 0.5 \mathrm{~g}$ yeast extract, $2.86 \mathrm{mg} \mathrm{H} \mathrm{BO}_{3}, 0.039 \mathrm{mg} \mathrm{Na} \mathrm{Mo}_{4} \cdot 2 \mathrm{H}_{2} \mathrm{O}, 0.222 \mathrm{mg} \mathrm{ZnSO}_{4} \cdot 7 \mathrm{H}_{2} \mathrm{O}$, $1.81 \mathrm{mg} \mathrm{MnCl} 2 \cdot 4 \mathrm{H}_{2} \mathrm{O}, 0.074 \mathrm{mg} \mathrm{CuSO} \cdot 5 \mathrm{H}_{2} \mathrm{O}$, and $0.03 \mathrm{mg} \mathrm{CoCl}$. For the inoculation, algal cells and spores were counted using a hemocytometer (Hausser Scientific, Horsham, PA, USA) under a light microscope (DC5-163, National Optical, Schertz, TX, USA). Unless indicated, the initial microalgae and fungi inoculation concentration were $2.55 \times 10^{9}$ cells $/ \mathrm{L}$ and $8.50 \times 10^{6}$ spores $/ \mathrm{L}$, respectively.

\subsection{Analysis}

At the end of the co-cultivation process, samples were analyzed for pellet size and number, algal and fungal biomass concentration and glucose concentration. Pellet size and number were estimated after the pellets were separated from culture medium using a 35-mesh sieve (0.5-mm pore size); then photographs of the pellets were taken with a camera (DC C840, BenQ, GueiShan, Taiwan). Photographs were further processed using imageJ software (National Institutes of Health, Bethesda, MD, USA). The total cell biomass was determined gravimetrically by drying the centrifuged samples at $105{ }^{\circ} \mathrm{C}$ for $24 \mathrm{~h}$. In order to differentiate the algal/fungal biomass from co-culture samples, algal biomass was determined indirectly by measuring chlorophyll-a (Chl-a) concentration. Standard curves of Chl-a concentrations versus algal dry weight were generated to correlate these results $\left(r^{2}=0.99\right)$. Chlorophyll (Chl-a) concentration was spectrophotometrically determined by extractions with methanol solution $(90 \% \mathrm{v} / \mathrm{v})$ as described by Becker [16] using a Shimadzu UV spectrophotometer (UV-1800, Shimadzu, Kyoto, Japan). The fungal biomass was determined by the difference from the total biomass dry weight and the algae biomass. In order to standardize the analysis, pellet samples were homogenized using a vortex with glass beads. Glucose concentration was estimated using dinitrosalicylic acid (DNS) method [17]. The microalgae harvesting efficiency (\%) was estimated as the amount of microalgae biomass attached to the pellet divided by the total algae biomass. All microalgae/fungi co-cultures were done in triplicate and mean value and standard error of results was calculated to evaluate the difference between samples. Results were analyzed with statistic software SPSS. One-way analysis of variance was chosen for the treatment comparisons for each data set. All statistics was based on a confidence level of $95 \%$; therefore, $p$ values smaller than 0.05 was considered statistically significant.

\section{Conclusions}

Different conditions were studied on the co-culture of filamentous fungus (Aspergillus niger) and microalgae (Chlorella vulgaris) to evaluate their cell pelletization. The experiments showed the best culturing conditions for co-pelletization with more than $90 \%$ microalgae harvesting performance achieved. An organic carbon source was necessary to sustain the growth of fungi and to allow the harvesting of microalgae, even at conditions with light. The experiments also showed that glycerol and acetate can be used as carbon sources for co-pelletization, and glycerol was better than acetate in terms of harvesting efficiency, but that glucose remained the best carbon source. The microalgae and fungi in the co-culture competed nutrients in the heterotrophic conditions, but could form symbiotic relationship and obtain higher total biomass in the mixotrophic conditions. This research provides a solid background for future application of this technology for microalgae harvesting. 


\section{Acknowledgments}

The research is supported by Synthetic Ecology Program at University of Minnesota Biotechnology Institute.

\section{Author Contributions}

Sarman Oktovianus Gultom contributed to experimental design, data acquisition, results analysis, and manuscript preparation. Carlos Zamalloa contributed to experimental design, and results analysis. Bo Hu contributed to experimental design, results analysis and manuscript preparation.

\section{Conflicts of Interest}

The authors declare no conflict of interest.

\section{References}

1. Yang, C.; Hua, Q.; Shimizu, K. Energetics and carbon metabolism during growth of microalgal cells under photoautotrophic, mixotrophic and cyclic light-autotrophic/dark-heterotrophic conditions. Biochem. Eng. J. 2000, 6, 87-102.

2. Miao, X.; Wu, Q. Biodiesel production from heterotrophic microalgal oil. Bioresour. Technol. 2006, 97, 841-846.

3. Shelef, G.; Sukenik, A.; Green, M. Microalgae Harvesting and Processing: A Literature Review; Technical Report for Technion Research and Development Foundation Ltd: Haifa, Israel, August 1984.

4. Zhang, J.G.; Hu, B. A novel method to harvest microalgae via co-culture of filamentous fungi to form cell pellets. Bioresour. Technol. 2012, 114, 529-535.

5. Zhou, W.; Cheng, Y.; Li, Y.; Wan, Y.; Liu, Y.; Lin, X.; Ruan, R. Novel fungal pelletization-assisted technology for algae harvesting and wastewater treatment. Appl. Biochem. Biotechnol. 2012, 167, 214-228.

6. Xia, C.; Zhang, J.; Zhang, W.; Hu, B. A new cultivation method for microbial oil production: Cell pelletization and lipid accumulation by Mucor circinelloides. Biotechnol. Biofuels 2011, 4, 15.

7. Zhou, W.G.; Min, M.; Hu, B.; Ma, X.C.; Liu, Y.H.; Wang, Q.; Shi, J.; Chen, P.; Ruan, R. Filamentous fungi assisted bio-flocculation: A novel alternative technique for harvesting heterotrophic and autotrophic microalgal cells. Sep. Purif. Technol. 2013, 107, 158-165.

8. Mackay, S.; Pereira Gomes, E.; Rossi, P.; Schwitzguebel, J.P.; Holliger, C. Pelletization of micro-algae by induced lichen formation through co-culture with filamentous fungi. In Proceedings of 5th Swiss Microbial Ecology Meeting, Murten, Switzerland, 4-6 February 2013.

9. Lustigman, B.; Lee, L.H.; Khalil, A. Effects of nickel and pH on the growth of Chlorella vulgaris. Bull. Environ. Contam. Toxicol. 1995, 55, 73-80.

10. Nielsen, J. Modelling the growth of filamentous fungi. In Modern Biochemical Engineering; Springer: Berlin/Heidelberg, Germany, 1992; Volume 46, pp. 187-223.

11. Liang, Y.N.; Sarkany, N.; Cui, Y. Biomass and lipid productivities of Chlorella vulgaris under autotrophic, heterotrophic and mixotrophic growth conditions. Biotechnol. Lett. 2009, 31, 1043-1049. 
12. Metz, B.; Kossen, N.W.F. The growth of molds in the form of pellets-A literature review. Biotechnol. Bioeng. 1977, 19, 781-799.

13. Zmak, P.M.; Podgornik, A.; Podgornik, H.; Koloini, T. Impact of pellet size on growth and lignin peroxidase activity of Phanerochaete chrysosporium. World J. Microbiol. Biotechnol. 2006, 22, $1243-1249$.

14. Heredia-Arroyo, T.; Wei, W.; Hu, B. Oil Accumulation via Heterotrophic/Mixotrophic Chlorella protothecoides. Appl. Biochem. Biotechnol. 2010, 162, 1978-1995.

15. Heredia-Arroyo, T.; Wei, W.; Ruan, R.; Hu, B. Mixotrophic cultivation of Chlorella vulgaris and its potential application for the oil accumulation from non-sugar materials. Biomass Bioenergy 2011, 35, 2245-2253.

16. Becker, E.W. Microalgae: Biotechnology and Microbiology; Canbridge University Press: Canbridge, UK, 1995.

17. Xiong, W.; Li, X.F.; Xiang, J.Y.; Wu, Q.Y. High-density fermentation of microalga Chlorella protothecoides in bioreactor for microbio-diesel production. Appli. Microbiol. Biotechnol. 2008, $78,29-36$.

(C) 2014 by the authors; licensee MDPI, Basel, Switzerland. This article is an open access article distributed under the terms and conditions of the Creative Commons Attribution license (http://creativecommons.org/licenses/by/3.0/). 